\title{
The Genetics of Penicillinase Production in Staphylococcus aureus Strain PS 80
}

\author{
By ELIZABETH H. ASHESHOV \\ Central Public Health Laboratory, Colindale Avenue, London, N.W.9
}

(Accepted for publication 3 September 1969)

\begin{abstract}
SUMMARY
PS 80 is a naturally occurring, penicillinase-producing strain of Staphylococcus aureus, which differs from the majority of such strains in that the genetic determinants for penicillinase production are located on the chromosome. The strain is also resistant to various metal ions and the genes controlling these resistances are located on a plasmid-the $\pi$ plasmid. When the strain is maintained on nutrient agar slopes at room temperature, a change occurs in its genetic constitution in that these unlinked genetic elements become closely linked and co-transducible with a high frequency. The results described in this paper are consistent with the hypothesis that the change is due to a duplication of the penicillinase genes with one copy of the genes being retained in its original chromosomal location and the other copy being incorporated in the $\pi$ plasmid.
\end{abstract}

\section{INTRODUCTION}

In most penicillinase-producing strains of Staphylococcus aureus the genetic determinants for penicillinase production are on extrachromosomal particles or plasmids (Novick, 1963). In addition to the penicillinase genes these plasmids often carry genes controlling resistance to mercury (Richmond \& John, I964), arsenate, arsenite, cadmium, lead and zinc ions (Novick \& Roth, I968) and, in a few strains isolated in Japan, to erythromycin (Hashimoto, Kono \& Mitsuhashi, 1964). Richmond (I968) has defined I I different types of penicillinase plasmids based on the type of penicillinase produced (Richmond, I965a), the degree of extracellularity of the enzyme, and the presence or absence of the genes controlling other resistance markers on the same plasmid. These plasmids have been divided into two compatibility groups (Com I and II) (Novick \& Richmond, 1965; Richmond, I965 b). Plasmids belonging to the same compatibility group are incompatible with each other in that they are unable to co-exist in the same cell to form stable plasmid diploids. Stable plasmid diploids can only be constructed when the two plasmids belong to different compatibility groups (Richmond, $1965 b$ ). The reason for this lack of compatibility is not known but an attachment site hypothesis, similar to that proposed for replicons in Escherichia coli by Jacob, Brenner \& Cuzin (1963), has been suggested. According to this, the plasmid has an attachment site, possibly on the cell membrane, to which the plasmid must become fixed in order to be stabilized and to ensure its equal distribution to progeny cells on division. Plasmids of Com I are assumed to have a Com I attachment site while plasmids of Com II have a second, equally specific attachment site. Some confirmation of this hypothesis has been provided by experiments of 
Novick (1967) and Richmond (1968) from which it appears that plasmids have a genetic locus, originally designated $m c$ (for maintenance and compatibility) but now designated $m c r$ (for maintenance, compatibility and replication) (Novick, I969), which is responsible for recognizing the cellular attachment site for the particular plasmid and allowing its autonomous replication. In plasmids of Com I, the gene is known as $m c r-I$ and in plasmids of Com II as $m c r-2$.

Although the genetic determinants for penicillinase production are on plasmids in most strains of staphylococci, a few strains have been described in which these genes probably have a chromosomal location (Asheshov, I966a: Poston, 1966: Harmon, Baldwin, Tien \& Critz, I966: Miller \& Harmon, I967). One of these strains is PS 80 (NCTC9789), the propagating strain for typing phage 80. Some of its characters were described previously (Asheshov, I966a) and may be summarized as follows. The genes determining penicillinase production in this strain are unusually stable and attempts to isolate penicillinase-negative mutants have been unsuccessful. When these genes are introduced into a sensitive strain by transduction, the kinetics of transduction are those expected for chromosomal genes, i.e. the frequency of transduction is low but can be increased by giving the transducing phage small doses of ultraviolet light (Arber, 1960). Strain PS80 is resistant to arsenate, arsenite, cadmium and mercury ions and the genes controlling these resistances appear to be carried on a plasmid. Mutants sensitive to all of these metal ions arise spontaneously with a fairly high frequency but these mutants continue to produce penicillinase.

In the original transduction experiments in which PS 80 was the donor of the penicillinase genes, co-transduction of resistance to the metal ions did not occur, which appeared to confirm the lack of linkage of these genes to the penicillinase genes. Further experiments have since been carried out, however, and it now appears that the genes controlling resistance to metal ions can become linked to the penicillinase genes, and under these conditions co-transduction of all these genetic elements occurs with a high frequency. The results to be described support the view that the plasmid in PS 80 which carries the genes controlling metal ion resistances is able to incorporate penicillinase genes into its structure without causing a deletion of these genes from the chromosome. The strain thus appears to change from a penicillinase haploid strain to a penicillinase diploid strain.

\section{METHODS}

Strains of Staphylococcus aureus. Strain PS80. Wild-type PS80 is an inducible penicillinase producer and is resistant to arsenate, cadmium and mercury ions. Its genotype is defined as $i^{+} p e n^{+}$( $\pi$ asa-r, cad-r, mer-r). In defining the genotype I have used the convention of Novick \& Richmond (1965) with some of the modifications suggested by Novick (1969). The symbol pen ${ }^{+}$refers to the structural gene for penicillinase and $i$ the penicillinase inducibility locus, $i^{+}$representing wild-type inducible synthesis and $i^{-}$mutant constitutive synthesis; asa-r, cad-r and mer-r refer to the loci determining resistance to arsenate, cadmium and mercury respectively and their sensitive alleles are designated asa-s, cad-s and mer-s. Plasmid genes are enclosed in parenthesis and the Greek letter, designating the type of plasmid, precedes the markers carried by the plasmid.

Strain 17855 . This strain was used as the recipient in all transduction experiments. It was kindly provided by Dr K. G. H. Dyke, who suggested its use. It is a 
penicillinase-negative mutant of a strain which originally produced penicillinase and is resistant to arsenate and cadmium ions but sensitive to mercury ions. The genes controlling resistance to arsenate and cadmium are chromosomal (Dyke, personal communication).

Cultures were maintained on nutrient agar slopes at room temperature and were subcultured at 3-monthly intervals. At the time of subculture the strains were phagetyped and their antibiotic resistance pattern was determined.

Phages. Typing phage 80 (NCTC 9788) was used as the transducing phage in all experiments. It was propagated on the donor strains using the soft-agar layer method of Swanstrom \& Adams (I95I). Lysates were sterilized by filtration through sintered glass filters (a.p.d. $\mathrm{I} \cdot 5 \mu$ ) and were stored at $4^{\circ}$.

The various preparations are designated by the phage number followed by the number of the strain on which propagation was carried out; for example, 80.80 indicates phage 80 propagated on strain Ps 80 . Batches of the various phages, propagated at different times, are further specified by a number in parenthesis.

Media. Nutrient broth and nutrient agar were prepared from Oxoid Nutrient Broth No. 2. Nutrient agar was solidified with $\mathrm{I} \cdot 2 \%$ (w/v) fibre agar. Peptone-water agar contained Oxoid peptone $20 \mathrm{~g}$.; $\mathrm{NaCl} 5 \mathrm{~g}$.; and Davis agar Io g. (pH 7.4). Starch agar was prepared by adding soluble starch to a final concentration of $0.2 \%(w / v)$ to either nutrient agar or peptone-water agar. It was used to detect penicillinase production.

Tests for resistance to penicillin and metal ions. Strains were tested for resistance either by the disc test or by plating on agar containing the different substances in suitable concentration. Discs contained the various substances in the following amounts: penicillin, I. 6 units of benzyl penicillin; arsenate ions, $0.32 \mathrm{mg}$. sodium arsenate; cadmium ions, $20 \mu \mathrm{g}$. cadmium sulphate; mercury ions, $0 \cdot 13 \mu \mathrm{g}$. phenyl mercuric nitrate.

Agar plates containing the various inhibitory substances were used for testing individual colonies, for replica-plating, and for isolating transductants growing from single cells. A single concentration was adequate for all these purposes except when testing for resistance to mercury ions. However, the test for mercury resistance is influenced by inoculum size, and a concentration of mercuric chloride suitable for use with relatively large inocula-e.g. when streaking growth from a colony or for replicaplating - was too high to allow growth from single cells, as in transduction experiments. It was necessary to use two different concentrations of mercuric chloride. The final concentrations used were as follows: penicillin, $0 . \mathrm{I} \mu \mathrm{g}$ benzyl penicillin $/ \mathrm{ml}$; cadmium ions, Io $\mu$ g. cadmium sulphate/ml.; mercury ions, $45 \mu \mathrm{g}$. $\mathrm{HgCl}_{2} / \mathrm{ml}$. (high concentration), $25 \mu \mathrm{g}$. $\mathrm{HgCl}_{2} / \mathrm{ml}$. (low concentration).

Either nutrient agar or peptone-water agar was used in testing for resistance to all of the substances except mercuric chloride. It was necessary to use peptone-water agar when testing for mercury resistance since the composition of the medium is critical (Moore, 1960; Green, 1962). Sodium citrate $\left(\mathrm{IO}^{-2} \mathrm{M}\right)$ was added to the agar when plates were used to isolate transductants, to inhibit lysis by free phage particles.

Tests for penicillinase production. Strains were recognized as penicillinase producers by their reaction on starch agar (Dyke, Jevons, \& Parker, I966). When penicillinasenegative mutants were being selected, methicillin $(0.5 \mu \mathrm{g} . / \mathrm{ml}$.) was added as an inducer of penicillinase. In the absence of inducer the test allows one to distinguish between 
inducible and constitutive penicillinase production. Quantitative estimations of penicillinase were carried out by the method of Richmond, Parker, Jevons \& John (I964).

Loss of drug resistance during growth at $37^{\circ}$ and $43.5^{\circ}$. The method used was essentially the same as that described previously (Asheshov, I966 b). The only modification was that, in some instances, penicillinase-negative mutants were sought by plating on starch-agar plates containing inducer rather than by replicating to penicillin agar. This allowed more clones to be screened in a single experiment.

Growth in the presence of acridine dyes. Log.-phase broth cultures, containing approximately $10^{8}$ viable units $/ \mathrm{ml}$. were diluted $\mathrm{IO}^{-4}$ in nutrient broth $(\mathrm{pH} 7.6)$ containing concentrations of 5 -amino acridine $\mathrm{HCl}$ ranging from 25 to $3 \cdot 125 \mu \mathrm{g}$. $/ \mathrm{ml}$. After incubation at $37^{\circ}$ for $18 \mathrm{hr}$, the tube containing the highest concentration of dye in which visible growth occurred was suitably diluted and plated on nutrient agar. Colonies were tested for drug-resistance by replica-plating to drug-containing medium.

Transduction experiments. These were carried out as described previously (Asheshov, I966a). In the majority of experiments the transducing phage was irradiated with u.v. light before being used to transduce. Five ml. of the phage suspension, diluted in nutrient broth, were placed in a sterile Petri dish at a distance of $23 \mathrm{~cm}$. from the light source, a I 5 W' 'germicidal' lamp. After each dose, a sample was removed, titrated for survivors, and used to transduce. In some experiments, transduction of two different markers was measured by dividing the phage-treated suspension into two equal portions and screening each for a different marker. The frequency of transduction was calculated as the ratio of the number of transductants obtained to the number of plaque-forming units used in the experiment.

The use of ethyl methane sulphonate to produce mutations. The method used was the same as that described by Novick (1963). After treatment, the cultures were screened on starch agar, with or without inducer, depending on whether mutations in the structural gene or the inducibility locus were being sought.

\section{RESULTS}

Stability of the genes controlling penicillinase production and resistance to metal ions in PS80. Old laboratory cultures of PS 80 were found to contain a small number of mutants that were sensitive to arsenate, cadmium and mercury ions but were still penicillinase producers. The frequency of loss of these markers could be increased, either by growth at $43.5^{\circ}$ or in the presence of 5 -amino acridine $\mathrm{HCl}$ (Table $\mathrm{I}, 2$ ). All of these mutants produced penicillinase. A more determined attempt was made to isolate penicillinase-negative mutants from Ps 80 after growth for $6 \mathrm{hr}$ at $43.5^{\circ}$. However, out of about 84,000 colonies examined in a single experiment, no penicillinase-negative mutants were detected.

Transduction experiments. A transduction experiment in which PS 80 was the donor of the genes controlling penicillin and mercury resistance to strain 17855 was done in I 965 using phage 80.80 (I) as transducing phage. Frequency of transduction is plotted as a function of the u.v. dose given to the transducing phage (Fig. I).

Transduction of the genes for penicillin resistance showed the curve expected for transduction of chromosomal genes in that there was a marked stimulation in frequency with small doses of u.v. light (Arber, 1960). The curve for transduction of mercury resistance was typical for transduction of extrachromosomal genes. Trans- 
ductants were examined for co-transduction of the opposite unselected marker but no co-transduction of penicillin and mercury resistance was found.

In early 1966 a second preparation of phage was made - phage $80.80(2)$-and the experiment was repeated. The kinetics of transduction of the two markers were similar to those obtained with the first phage preparation. However, when transductants, selected for penicillin resistance, were examined it was found that a minority (about $15 \%$ ) had been co-transduced to mercury resistance.

Table I. Effect of growth at $37^{\circ}$ and $43.5^{\circ}$ on the loss of resistance to cadmium ions in $P S 80$

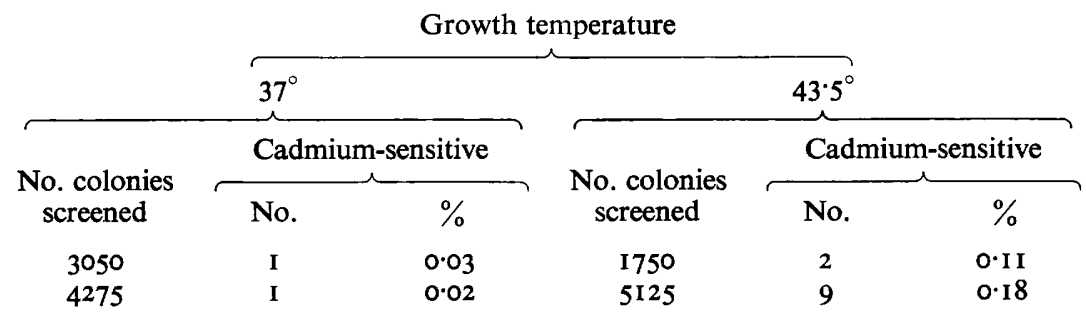

The results of two independent experiments are given.

Table 2. Effect of growth in 5-amino acridine $\mathrm{HCl}$ on the loss of resistance to cadmium ions in PS80

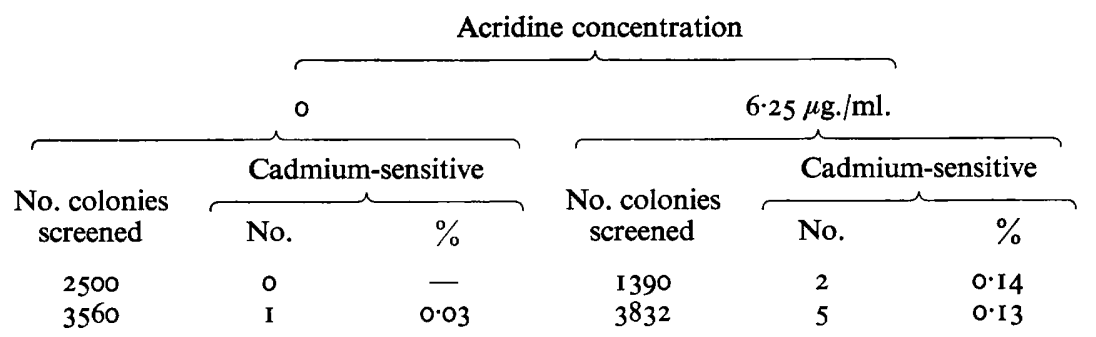

The results of two independent experiments are given.

Table 3. A comparison of the frequency of transduction of penicillin resistance and co-transduction of penicillin and mercury resistance with five different batches of phage $80 / 80$ (recipient: strain 17855)

$\begin{array}{cc}\text { Batch no. } & \begin{array}{c}\text { Date of } \\ \text { preparation }\end{array} \\ \text { I } & 1965 \\ 2 & \text { Feb. I } 966 \\ 3 & \text { Apr. } 1966 \\ 4 & \text { Aug. } 1966 \\ 5 & \text { Feb. } 1967\end{array}$

$\begin{array}{cc}\text { Penicillin-resistance } & \begin{array}{c}\text { Penicillin and } \\ \text { mercury resistance }\end{array} \\ \mathrm{I} \cdot 5 \times 10^{-8} & <7.5 \times 10^{-9} \\ 4 \cdot 5 \times 10^{-9} & 4.5 \times 10^{-9} \\ 7.5 \times 10^{-9} & 9 \cdot 2 \times 10^{-8} \\ 9 \cdot 4 \times 10^{-9} & 9 \cdot 4 \times 10^{-8} \\ \mathrm{I} \cdot 0 \times 10^{-8} & 3.5 \times 10^{-6}\end{array}$

Three more preparations of phage 80.80 were made subsequently and their ability to transduce penicillin resistance and to co-transduse penicillin and mercury resistance was determined (Table 3). Only frequencies with unirradiated phage are given. The frequency of transduction of penicillin resistance alone remained more or less the same 
throughout these experiments. Frequency of co-transduction, however, increased strikingly during the 20 months elapsing between the preparation of the first and the fifth batch of phage.

Figure 2 shows the frequencies obtained for transduction of penicillin resistance alone, mercury resistance alone and the co-transduction frequency for both resistances obtained with the fifth batch of phage. The curve obtained for transduction of penicillin resistance showed the usual kinetics for chromosomal genes and resembled that obtained with the first batch of phage (cf. Fig. I). The curve obtained for transduction of mercury resistance was also similar to that found with the first batch of phage. The curve for co-transduction of both resistance markers showed the exponential decrease expected for extrachromosomal genes with a slightly lower frequency than that found for transduction of mercury resistance.

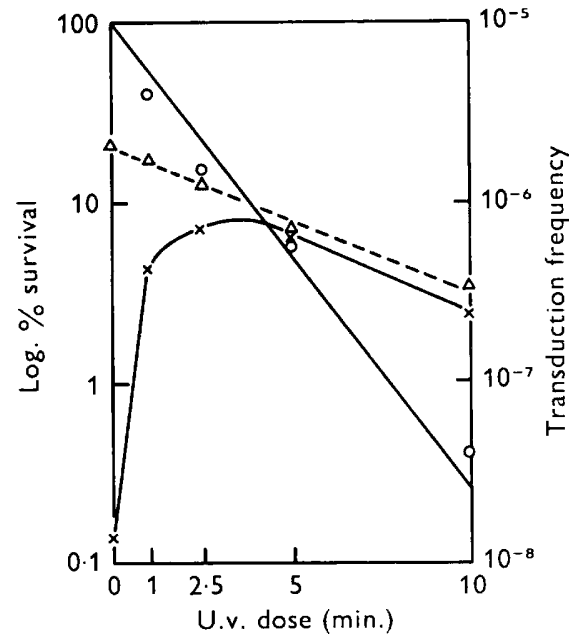

Fig. I

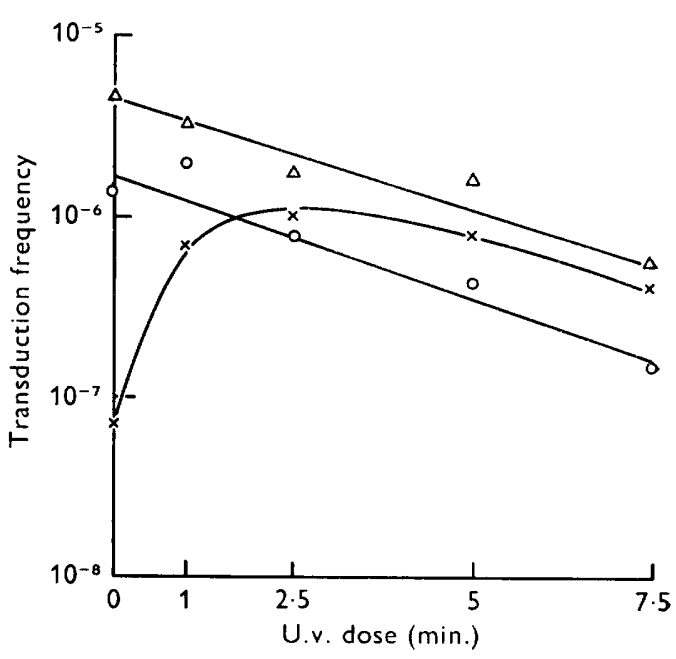

Fig. 2

Fig. I. Frequency of transduction of penicillin and mercury resistance plotted as a function of the u.v. dose given to the transducing phage, phage 80/80 (I). Recipient: strain 17855 . Donor: Ps 80. Phage inactivation curve: $\bigcirc-O$. Transduction of penicillin resistance: $x-\times$. Transduction of mercury resistance: $\triangle \cdots \triangle$.

Fig. 2. Frequency of transduction of penicillin resistance, mercury resistance and cotransduction of both resistances obtained with phage 80/80(5). Recipient: strain 17855 . Frequencies are plotted as a function of the u.v. dose given to the transducing phage. Transduction of penicillin resistance: $x-\times$. Transduction of mercury resistance: $\triangle \longrightarrow \triangle$. Co-transduction of both resistances: $O-0$.

The results suggested that the phage preparation used in this experiment contained three sorts of transducing particles: those carrying only the chromosomal penicillinase genes, those carrying the plasmid genes controlling resistance to the metal ions, and a third class carrying the genetic determinants for both penicillin and mercury resistance linked together. The simplest explanation to account for the presence of three different sorts of transducing particles would seem to be that the donor was heterogeneous and consisted of some cells in which these genes were linked and others in which they were unlinked.

This was confirmed by propagating phage 80 on ten well-isolated colonies of 
PS 80 and determining the ability of these ten preparations to transduce penicillin resistance and to co-transduce penicillin and mercury resistance (Table 4). Four of the phages co-transduced both resistances with a high frequency, four showed little or no co-transduction and the other two gave intermediate co-transduction frequencies.

This phenomenon was not confined to the particular culture of PS 80 used in these experiments. A mutant of PS 80 which produced penicillinase constitutively was isolated in 1965 after treatment of the wild-type strain with ethyl methane sulphonate (EMS). This mutant was used as the donor of the penicillinase genes soon after its isolation and, at that time, it failed to show any co-transduction of penicillin and mercury resistance. A second preparation of phage 80 was made in 1967 and this preparation co-transduced both resistances with a high frequency.

Table 4. Frequency of transduction of penicillin resistance and co-transduction of penicillin and mercury resistance to strain 17855 with phage 80 propagated on Io different clones of PS 80

Phage
preparation
I
2
3
4
5
6
7
8
9
10

Frequency of transduction of

$\begin{array}{cc}\text { Penicillin resistance } & \begin{array}{c}\text { Penicillin and } \\ \text { mercury resistance }\end{array} \\ \mathrm{I} \cdot 0 \times 10^{-7} & \mathrm{I} \cdot \mathrm{I} \times 1 \mathrm{I}^{-5} \\ 9.0 \times \mathrm{IO}^{-8} & 2.9 \times 10^{-6} \\ 2.0 \times 10^{-7} & 2.0 \times 10^{-5} \\ 2.0 \times 10^{-8} & <\mathrm{I} \cdot 0 \times 10^{-8} \\ 8.0 \times 10^{-8} & 5.0 \times 10^{-8} \\ 3.0 \times 10^{-8} & <3.0 \times 10^{-9} \\ 4.8 \times 10^{-8} & 3.2 \times 10^{-8} \\ 9.9 \times 10^{-8} & 2.5 \times 10^{-8} \\ 7.0 \times 10^{-8} & <5.0 \times 10^{-8} \\ 9.6 \times 10^{-8} & 8.6 \times 10^{-7}\end{array}$

Linkage of the genetic determinants for penicillin and metal ion resistances in PS 80. There appear to be two possible explanations of the change that has occuured in the genetic constitution of PS 80 during the course of these experiments. The simplest one is that one or other of these originally unlinked genetic elements has changed its cellular location-either the penicillinase genes have been excised from the chromosome and incorporated into the structure of the $\pi$ plasmid, or the $\pi$ plasmid has integrated into the chromosome at a site sufficiently close to the penicillinase genetic region to allow co-transduction of all these genes with a high frequency. The second possibility is that duplication of the penicillinase genes has occurred with one copy being retained in its original chromosomal location and the second copy being integrated into the $\pi$ plasmid.

If the first explanation is correct it should be reflected in a change in the stability of the genes involved. The stability of the penicillinase genes is presumably due to their chromosomal location. If they have been excised from the chromosome and become part of the $\pi$ plasmid they should show the same instability as the $\pi$ plasmid and it should be possible to isolate penicillinase-negative mutants with a reasonably high frequency. If, on the other hand, linkage has occurred through integration of the $\pi$ plasmid into the chromosome this should have the effect of stabilizing these genes.

Two sub-lines of PS 80 were chosen for study. These are isolates number 3 and 4 of Table 4. Isolate number 3 showed a high frequency of co-transduction of penicillin 
and mercury resistance and should, therefore, be a strain in which most of the cells carry the genes controlling these resistances closely linked. It will be referred to as PS 80 HCD (high co-transducing donor). Isolate number 4 was a strain which showed no co-transduction of these resistances and, presumably in this strain these genes are unlinked. It will be referred to as PS 80 LCD (low co-transducing donor).

Table 5. Loss of resistance to cadmium ions in PS8OHCD and PS8OLCD after growth at $43.5^{\circ}$ and in the presence of $6.25 \mu \mathrm{g} . / \mathrm{ml}$. of 5-amino acridine $\mathrm{HCl}$

\begin{tabular}{|c|c|c|c|c|c|c|}
\hline \multirow[b]{3}{*}{ Treatment } & \multicolumn{3}{|c|}{ Control culture } & \multicolumn{3}{|c|}{ Treated culture } \\
\hline & \multirow{2}{*}{$\begin{array}{c}\text { No. } \\
\text { colonies } \\
\text { screened }\end{array}$} & \multicolumn{2}{|c|}{ Cadmium-sensitive } & \multirow{2}{*}{$\begin{array}{l}\text { No. } \\
\text { colonies } \\
\text { screened }\end{array}$} & \multicolumn{2}{|c|}{ Cadmium-sensitive } \\
\hline & & No. & $\%$ & & No. & $\%$ \\
\hline \multicolumn{7}{|c|}{ Ps $80 \mathrm{HCD}$} \\
\hline $\begin{array}{l}43.5^{\circ} \\
43.5^{\circ} \\
\text { Acridine } \\
\text { Acridine }\end{array}$ & $\begin{array}{l}3015 \\
3210 \\
4500 \\
4400\end{array}$ & $\begin{array}{r}3 \\
18 \\
2 \\
14\end{array}$ & $\begin{array}{l}0.10 \\
0.56 \\
0.04 \\
0.31\end{array}$ & $\begin{array}{r}945 \\
2350 \\
3110 \\
4440\end{array}$ & $\begin{array}{r}7 \\
13 \\
11 \\
78\end{array}$ & $\begin{array}{l}0.74 \\
0.55 \\
0.35 \\
I .53\end{array}$ \\
\hline \multicolumn{7}{|c|}{ PS 80 LCD } \\
\hline $43 \cdot 5^{\circ}$ & 3530 & 0 & - & 750 & 2 & 0.26 \\
\hline $43 \cdot 5^{\circ}$ & 3050 & $\mathbf{I}$ & 0.03 & 1750 & 2 & O.II \\
\hline Acridine & 2170 & 0 & - & 2000 & 0 & - \\
\hline Acridine & 3560 & I & 0.03 & 3832 & 5 & 0.13 \\
\hline
\end{tabular}

PS 80 HCD was first examined for stability of the penicillinase genes after growth at $43.5^{\circ}$ for $6 \mathrm{hr}$. Approximately $10^{6}$ clones were screened in a single experiment but no penicillinase-negative mutants were detected. It would seem, therefore, that there has been no change in the stability of the penicillinase genes in PS $80 \mathrm{HCD}$, which suggests that they are still chromosomal.

The stability of the genes controlling resistance to the metal ions was then examined in PS $80 \mathrm{HCD}$ and PS $80 \mathrm{LCD}$ after growth at $43.5^{\circ}$ for $6 \mathrm{hr}$ and after growth in 5-amino acridine $\mathrm{HCl}$ for $\mathrm{I} 8 \mathrm{hr}$. The genes controlling metal ion resistances in PS $80 \mathrm{HCD}$ showed a slightly increased instability compared with PS 80 LCD (Table 5). There was thus no evidence that either the penicillinase genes or the genes controlling resistance to the metal ions had changed their location in the cell.

The second possibility-that PS 80 had changed from a penicillinase haploid to a diploid strain-was examined. It is possible to construct stable penicillinase diploids in PS 80 in which one copy of the genes is on the chromosome and the other on a plasmid. The behaviour of two such diploids was described by Asheshov \& Dyke (I968). These diploids were constructed by transducing the linked genes for penicillin and metal ion resistances, using a high co-transducing isolate of PS 80 as the donor, into PS 80 recipients which had lost the $\pi$ plasmid after growth at $43.5^{\circ}$. Transductants were selected for cadmium resistance. The recipient and donor strains chosen for these experiments carried different alleles of the inducibility locus, i.e. when the recipient was $i^{+}$pen+, the donor was $i^{-}$pen+ and vice versa. It was found that when the $i^{+}$gene was on the plasmid and the $i^{-}$allele on the chromosome the diploids were phenotypically inducible, judging both by their reaction on starch agar and by the level of enzyme produced in the absence of inducer. The plasmid $i^{+}$gene was able to exert control trans on the chromosomal genes. However, when the location of these alleles 
was reversed, the chromosomal $i^{+}$gene exerted only partial control on the plasmid $i^{-} p^{-} n^{+}$genes. These latter diploids appeared to be constitutive enzyme producers, judging by their reaction on starch agar. However, the level or penicillinase produced in the absence of inducer, though significantly higher than the basal level characteristic of normal inducible strains, was lower than that expected for constitutive strains. A gene dose hypothesis has been postulated to explain this positional effect (Asheshov \& Dyke, 1968).

In order to show that Ps $80 \mathrm{HCD}$ carried two copies of the penicillinase genes it was necessary to introduce a mutation into one of the copies. It was argued that it should be possible to produce a mutation in the $i$ gene of the plasmid which would cause the strain to appear constitutive on starch agar. Such a 'constitutive' should resemble the partial constitutive diploids constructed artificially in PS 80 and should revert to an inducible phenotype on losing the genes controlling resistance to the metal ions. If PS $80 \mathrm{LCD}$ is a penicillinase haploid strain, mutation to a constitutive phenotype would be expected to occur as the result of a mutation in the single chromosomal $i$ gene. Such a mutant should be fully constitutive and should retain this character on losing resistance to the metal ions.

Table 6. Transduction of penicillin resistance to strain 17855 from PS 8OHCD C-I and PS8OLCD C-I

The transducing phages were given varying doses of u.v. irradiation before being used to transduce.

\begin{tabular}{|c|c|c|c|c|}
\hline \multirow{2}{*}{$\begin{array}{l}\text { U.v. dose } \\
\text { (min.) }\end{array}$} & \multicolumn{4}{|c|}{ No. of transductants of the phenotype: } \\
\hline & $\mathrm{i}^{+}$pen + mer-s & $i^{-}$pen+mer-r & $\mathrm{i}^{+}$pen ${ }^{+}$mer-r & $\mathrm{i}^{-}$pen ${ }^{+}$mer-s \\
\hline \multicolumn{5}{|c|}{ Donor: Ps 80 LCD C-I } \\
\hline 0 & 0 & 0 & o & 20 \\
\hline I & $\circ$ & 0 & 0 & 393 \\
\hline 2.5 & 0 & 0 & 0 & 818 \\
\hline $5 \cdot 0$ & o & 0 & o & 707 \\
\hline \multicolumn{5}{|c|}{ Donor: PS $80 \mathrm{HCD}$ C-I } \\
\hline 0 & 6 & I I 73 & 8 & 2 \\
\hline I & 58 & 1193 & 12 & 2 \\
\hline $2 \cdot 5$ & 125 & 854 & II & 3 \\
\hline 5.0 & 247 & 666 & I & 3 \\
\hline
\end{tabular}

These two strains were treated with EMS and the survivors plated to starch agar. Three apparently constitutive mutants were isolated from each strain in two separate experiments. These were designated HCDC-I, C-2, C-3 and LCDC-I, c-2, and c-3. These six mutants were grown at $43.5^{\circ}$ and cadmium-sensitive segregants were isolated from each of them. The three HCD 'constitutives' all reverted to an inducible phenotype on losing resistance to the metal ions: the three LCD mutants retained their constitutive phenotype on losing resistance to the metal ions. These results strongly suggested that the HCD mutants were $i^{+} / i^{-}$diploids with the $i^{-}$allele on the $\pi$ plasmid.

Transduction experiments were done in which each of the six mutants was used as the donor of penicillin resistance to strain 17855 . Transductants were replica-plated to mercury agar containing starch, to allow determination of the penicillinase phenotype of any penicillin-resistant, mercury-resistant transductants. Mercury-sensitive trans- 
ductants were purified and their penicillinase phenotype determined on starch agar. The results of an experiment in which PS8OLCDC-I and HCDC-I were the donors are shown in Table 6.

All of the penicillin-resistant transductants obtained when the donor was PS 8OLCDC-I were constitutive and sensitive to mercury ions. The frequency of transduction was stimulated by u.v.-irradiation of the transducing phage. It would seem, therefore, that this donor carries a single copy of the penicillinase genes on the chromosome, unlinked to the metal ion resistance genes. When PS $80 \mathrm{HCDC}-\mathrm{I}$ was the donor, however, there were four phenotypically different classes of transductants: $i^{+}$pen ${ }^{+}$mer-s, $i^{-}$pen ${ }^{+}$mer-r, $i^{+}$pen ${ }^{+}$mer-r and $i^{-}$pen ${ }^{+}$mer-s. The majority belonged to the first two classes. The $i^{+}$pentmer-s linkage group showed the transduction kinetics expected for chromosomal genes while the $i^{-}$pen ${ }^{+}$mer-r linkage group showed the kinetics expected for extrachromosomal genes. The results are consistent with the view that PS8OHCDC-I is a penicillinase diploid with an $i^{+} p e n^{+}$linkage group on the chromosome and an $i^{-}$pen ${ }^{+}$linkage group on the $\pi$ plasmid. The presence of a few recombinant types- $i^{+}$pen ${ }^{+}$mer- $r$ and $i^{-}$pen ${ }^{+} m e r-s-i n d i c a t e s$ that there is a certain amount of recombination between the chromosomal and extrachromosomal penicillinase genes.

Table 7. Quantitative determination of penicillinase produced by strains $P S 8 O H C D$, PS8OLCD, PS8OHCD C-I, PS8OLCD C-I, and transductants obtained from the latter two strains

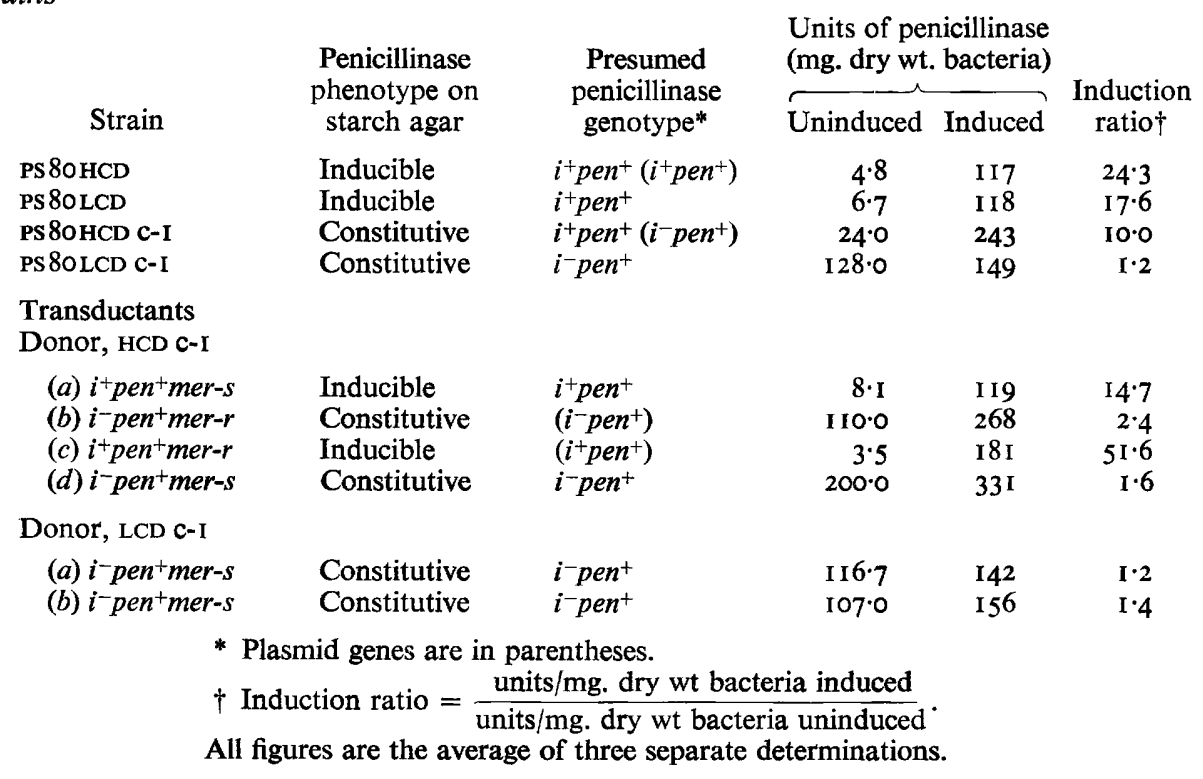

Quantitative estimations of penicillinase produced by PS 80 HCDC-I and the four types of transductants obtained when this strain was used as donor were carried out. Similar determinations were made on PS 8OLCD C-I and two of the transductants obtained with this donor. Enzyme levels produced by PS $80 \mathrm{HCD}$ and LCD, the parent strains from which HCD C-I and LCD C-I were derived, are included for comparison (Table 7).

Strain LCD C-I is a magno-constitutive strain with an induction ratio of $I \cdot 2$, and 
the two transductants obtained from this strain show similar levels for uninduced and induced enzyme. Strain HCD c-1, however, is a partial constitutive, with an induction ratio of 10:I. The uninduced level of penicillinase produced by this strain, although significantly higher than that produced by the inducible parent, PS $80 \mathrm{HCD}$, is much lower than that expected for a fully constitutive strain. The presence of a chromosomal $i^{+}$gene is apparently exerting only partial control on enzyme synthesis. Segregation of the two penicillinase linkage groups carried by HCD C-I is apparent in the transductants obtained from this strain. The two phenotypically $i^{+} p e n^{+}$transductants show enzyme levels and induction ratios characteristic of wild-type inducible strains, while the two $i^{-}$pen $^{+}$transductants have enzyme levels and induction ratios characteristic of magno-constitutive strains. It is interesting that PS $80 \mathrm{HCD}$, a penicillinase diploid strain, and PS $80 \mathrm{LCD}$, a penicillinase haploid strain, produce the same amount of enzyme on induction, as though only one structural gene in PS $80 \mathrm{HCD}$ is being expressed. This is similar to results obtained by Richmond (1965b) for $i^{+} / i^{-}$plasmid diploids.

\section{DISCUSSION}

The conclusion that PS80 carries a copy of the penicillinase genes on the chromosome is based on several lines of evidence. First, the genes are unusually stable and attempts to isolate penicillinase-negative mutants have failed. Secondly, the kinetics of transduction of these genes are those expected for chromosomal genes. Finally, the fact that Ps 80 is able to form stable penicillinase diploids, not only with the $\alpha$ and $\gamma$ plasmid (unpublished results) but also with the homologous genes when they are incorporated into the $\pi$ plasmid, is consistent with this conclusion.

The same sort of evidence supports the conclusion that the genetic determinants for resistance to the various metal ions are carried on a plasmid in Ps 80 . These genes are unstable and are lost on storage, during growth at $43.5^{\circ}$, and in the presence of 5-amino acridine $\mathrm{HCl}$. Moreover, the transduction kinetics for these genes are those expected for extrachromosomal genes. The plasmid carrying these genes-the $\pi$ plasmid-has at least one characteristic in common with certain wild-type penicillinase plasmids in that it is unable to coexist with the $\gamma$ plasmid (unpublished results). It has, accordingly, been assigned to compatibility group I and is assumed to carry an $m c r-I$ locus in addition to its resistance markers.

Although the penicillinase genes are chromosomal in Ps 80 and the genes controlling resistance to metal ions are extra-chromosomal, these separate genetic elements can become closely linked when the strain is maintained on nutrient agar at room temperature. The experimental evidence indicates that this occurs through a duplication of the penicillinase genes, with one copy being retained on the chromosome and the other being integrated into the $\pi$ plasmid. A similar phenomenon was described by Ames, Hartman \& Jacob (1963) in a Salmonella strain in which the genes controlling histidine biosynthesis were duplicated, with the second copy being incorporated into a cryptic episome. Sweeney \& Cohen (1968) have recently described a wild-type strain of Staphylococcus aureus which resembles PS $80 \mathrm{HCD}$ both in the number and location of the penicillinase genes.

The ability of the $\pi$ plasmid to incorporate chromosomal genes suggests that, at some time, the plasmid becomes intimately associated with the chromosome. It may be that the $\pi$ plasmid has some regions genetically homologous with the chromosomal 
penicillinase genetic region. However, there is no evidence for this at the present time. The $\pi$ plasmid does not carry a functional pen gene. Neither does it appear to carry an intact $i^{+}$gene since its introduction into an $i \sim p e n^{+}$mutant of PS 80 , in which the penicillinase genes were chromosomal, failed to change the uninduced enzyme level. If the $\pi$ plasmid does associate with the chromosome, the association appears to be a transient one. Any permanent association would be expected to increase the stability of the genes carried by the plasmid. However, in PS $80 \mathrm{HCD}$ these genes were, if anything, more unstable than in PS 8OLCD.

\section{REFERENCES}

Ames, B. N., Hartman, P. E. \& JACOB, F. (1963). Chromosomal alterations affecting the regulation of histidine biosynthetic enzymes in Salmonella. J. molec. Biol. 7, 23.

ARBER, W. (1960). Transduction of chromosomal genes and episomes in Escherichia coli. Virology Ir, 273.

AsHeshov, E. H. (1966a). Chromosomal location of the genetic elements controlling penicillinase production in a strain of Staphylococcus aureus. Nature, Lond. 210, 804.

AsHESHOV, E. H. (1966b). Loss of antibiotic resistance in Staphylococcus aureus resulting from growth at high temperature. J. gen. Microbiol. 42, 403.

AsHESHOV, E. H. \& DYKE, K. G. H. (I968). Regulation of the synthesis of penicillinase in diploids of Staphylococcus aureus. Biochem. biophys. Res. Commun. 30, 213.

Dyke, K. G. H., Jevons, M. P. \& Parker, M. T. (1966). Penicillinase production and intrinsic resistance to penicillin in Staphylococcus aureus. Lancet i, 835.

Green, S. M. (1962). Mercury sensitivity of staphylococci. J. clin. Path. 15, 249.

Harmon, S. A., Baldwin, J. N., TIEN, W. C. \& Critz, D. B. (I966). Co-transduction of the genetic determinants of the synthesis of penicillinase and methionine in Staphylococcus aureus. Can.J. Microbiol. 12, 973.

Hashimoto, H., Kono, K. \& Mrtsuhash, S. (1964). Elimination of penicillin resistance of Staphylococcus aureus by treatment with acriflavine. J. Bact. 88, $26 \mathrm{I}$.

JACOB, F., BRENNER, S. \& CUZIN, F. (1963). On the regulation of DNA replication in bacteria. Cold Spring Harb. Symp. quant. Biol. $28,329$.

Miller, M. A. \& HARMON, S. A. (1967). Genetic association of the determinants controlling resistance to mercuric chloride, production of penicillinase and synthesis of methionine in Staphylococcus aureus. Nature, Lond. 215, 53 I.

MOORE, B. (1960). A new screen test and selective medium for a rapid detection of epidemic strains of Staphylocococcus aureus. Lancet ii, 453.

Novick, R. P. (1963). Analysis by transduction of mutations affecting penicillinase formation in Staphylococcus aureus. J. gen. Microbiol. 33, I2I.

Novick, R. P. (1967). Penicillinase plasmids of Staphylococcus aureus. Fedn Proc. Fedn Am. Socs exp. Biol. 26, 29.

Novick, R. P. (1969). Extrachromosomal inheritance in bacteria. Bact. Rev. 33, 210.

Novick, R. P. \& RICHMOND, M. H. (1965). Nature and interaction of the genetic elements governing penicillinase synthesis in Staphylococcus aureus. J. Bact. 9o, 467.

Novick, R. P. \& Roth, C. (I968). Plasmid-linked resistance to inorganic salts in Staphylococcus aureus. J. Bact. 95, I335.

Poston, S. M. (1966). Cellular location of the genes controlling penicillinase production and resistance to streptomycin and tetracycline in a strain of Staphylococcus aureus. Nature, Lond. $210,802$.

Richmond, M. H. (1965a). Wild-type variants of exopenicillinase from Staphylococcus aureus. Biochem. J. 94, 584 .

RuchmoND, M. H. (1965b). Dominance of the inducible state in strains of Staphylococcus aureus containing two distinct penicillinase plasmids. J. Bact. 90, 370.

Richmond, M. H. (I968). The plasmids of Staphylococcus aureus and their relation to other extrachromosomal elements in bacteria. In Adv. microb. Physiol. 2, 43. Ed. by A. H. Rose and J. F. Wilkinson. New York: Academic Press. 
Richmond, M. H. \& JoHN, M. (1964). Co-transduction by a staphylococcal phage of the genes responsible for penicillinase synthesis and resistance to mercury salts. Nature, Lond. 202, 1360 . Richmond, M. H., Parker, M. T., Jevons, M. P. \& John, M. (1964). High penicillinase production correlated with multiple antibiotic resistance in Staphylococcus aureus. Lancet i, 293.

Swanstrom, M. \& Adams, M. H. (195I). Agar layer method for production of high titer phage stocks. Proc. Soc. exp. Biol. Med. 78, 372.

SWEENEY, H. M. \& COHEN, S. (1968). Wild-type strain of Staphylococcus aureus containing two genetic linkage groups for penicillinase production. J. Bact. 96, 920. 